\title{
Bumblebee study called into question
}

Data reanalysis casts doubt on UK government stance on neonicotinoid pesticides.

\section{Daniel Cressey}

26 March 2015

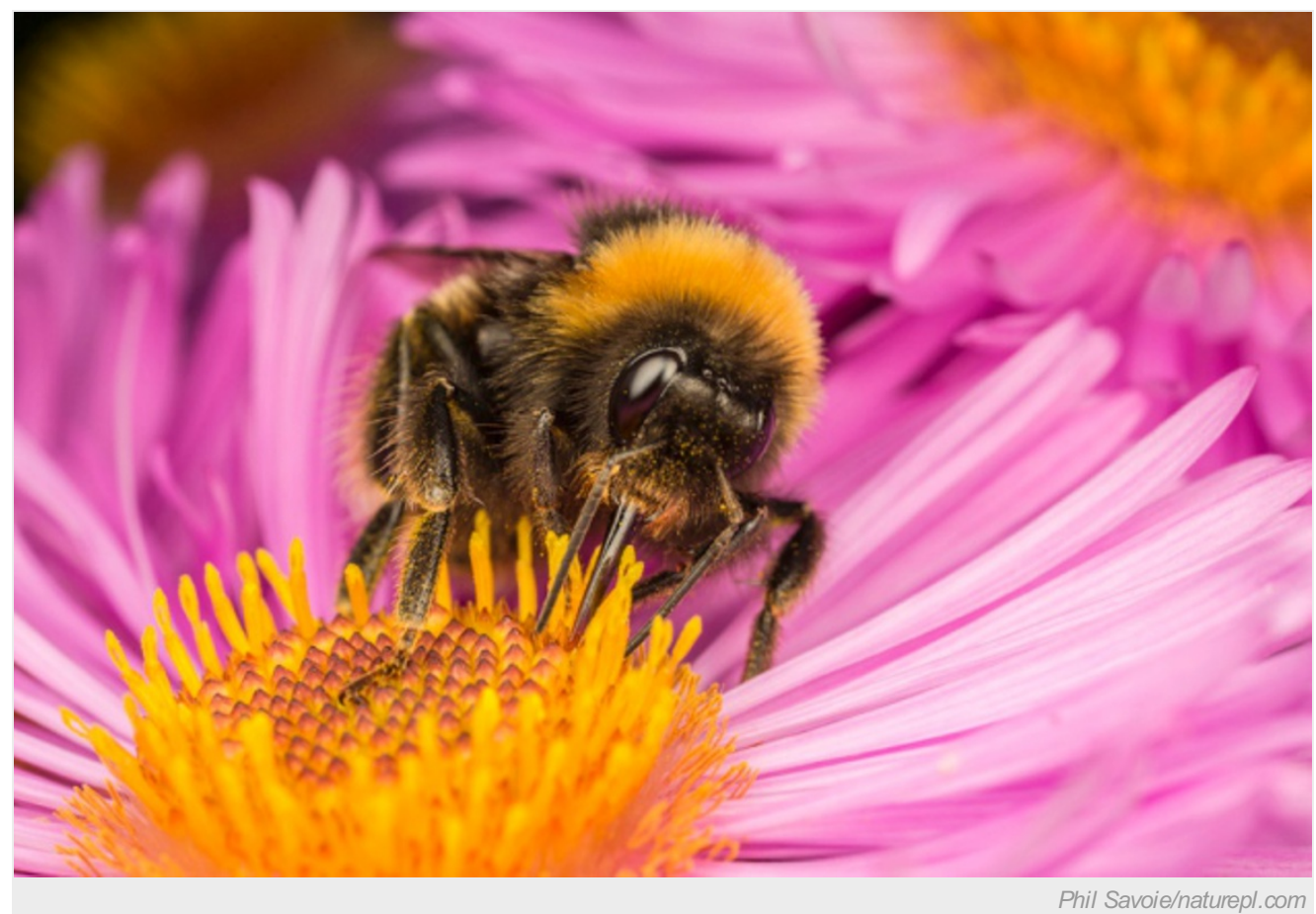

A buff-tailed bumblebee (Bombus terrestris) feeding at a flower. There is concern that neonicotinoids are damaging bee populations in Europe.

A fresh analysis of data from a controversial study which concluded that neonicotinoid pesticides do not harm bees has reached the opposite conclusion, casting doubt on the UK government's policy on the chemicals.

Neonicotinoids have been shown in a number of laboratory studies to harm bees, but there is little evidence from actual 'field-realistic' conditions. The European Commission has restricted the use of these insecticides temporarily over fears about their harmful effects, but this action is opposed by the UK government. Despite its opposition, Britain was forced to comply with the ban under European Union (EU) rules. The ban is due for review in later this year.

A key piece of evidence informing the UK government's position is a study published in 2013 by Britain's Food and Environment Research Agency (FERA). This found "no clear consistent relationships" between exposure to neonicotinoids and the growth of bee colonies and the 
number of queens they produce ${ }^{1}$. But Dave Goulson, a bee researcher at the University of Sussex in Falmer, UK, has reanalysed the FERA data and concluded that they actually show substantial negative effects of neonicotinoids on the performance of colonies ${ }^{2}$.

"I would argue they didn't correctly interpret their own results," says Goulson, who supports the EU moratorium on neonicotinoid use.

\section{Negative impacts}

The FERA team monitored the development of 60 colonies of bumblebees (Bombus terrestris audax) at three research sites. They placed 20 colonies next to a field containing crops grown from seeds treated with the neonicotinoid clothianidin, 20 next to a field treated with another neonicotinoid called imidacloprid, and 20 next to an untreated field. For part of the analysis, the FERA team used a model to investigate whether there was a relationship between the colonies' health and the level of neonicotinoids stored in their hives. Their results found no such pattern.

Goulson's main problem with the FERA method is that when no insecticides were detected in a colony, the researchers randomly assigned a value of between zero and the limit below which they were unable to detect the chemical, and these simulated pesticide levels were used when they ran 1,000 simulations with their model. Goulson used a related but simpler model that assumed that 'no pesticide detected' meant either that none was present or that the pesticide was present but below the detectable limit. In both cases, this simpler analysis found statistically significant negative impacts on bees from neonicotinoids.

"I don't suppose l'm on DEFRA's Christmas list," says Goulson, referring to the government's Department for Environment, Food \& Rural Affairs, which commissioned the FERA study. Goulson is urging the government to reconsider its opposition to a ban on these chemicals.

In a statement, DEFRA said that it was aware of the new analysis and recognized that pesticides are "one of the potential pressures" on bees. "We continue to work closely with the EU and our independent Advisory Committee on Pesticides to review any new research into the effects of neonicotinoids on bee populations, ensuring it is based on the best scientific evidence available," said the statement.

FERA welcomed Goulson's analysis, and stressed that the 2013 study stated that it lacked the power to reach any firm conclusions about neonicotinoids and bumblebees. "Whilst there was an absence of evidence to support the hypothesis that neonicotinoids harm bees, this does not lead to the conclusion that they are benign," said the agency.

Nature I doi:10.1038/nature.2015.17201

\section{References}

1. FERA. Effects of Neonicotinoid Seed Treatments on Bumble Bee Colonies Under Field Conditions (FERA, 2013); go.nature.com/W9JLtl

2. Goulson, D. PeerJ 3, e854; http://dx.doi.org/10.7717/peerj.854 (2015).

\section{SPRINGER NATURE}

